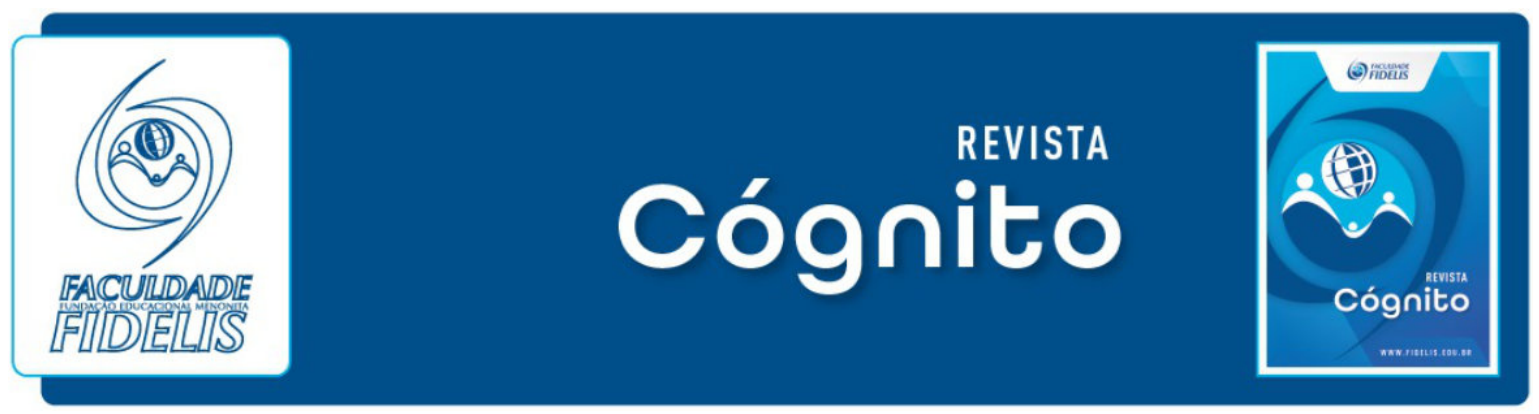

\title{
POLÍTICAS DE GÊNERO E DIREITOS DAS MULHERES: DIVERSIDADE E INCLUSÃO
}

Angela Natel ${ }^{1}$

\section{RESUMO}

O presente estudo aborda o tema das políticas de gênero e direitos das mulheres no contexto das Políticas Públicas no Brasil. No desenho das políticas de gênero, nosso país é signatário de vários acordos internacionais. Em suas políticas percorre uma trajetória transversal para enfrentar as desigualdades e diferenças sociais, raciais, sexuais e étnicas. As políticas de gênero são articuladas por diferentes setores do governo, se traduzem em mudanças na legislação, numa produção crescente de estudos sobre a incidência desse fenômeno, na redução das desigualdades entre homens e mulheres, na inclusão social, no empoderamento e na promoção da cidadania. $\mathrm{O}$ reconhecimento das mulheres como sujeito de direito e sujeito político é parte das propostas para as políticas de gênero que visam promover maior acesso e participação das mulheres nos espaços de poder, como uma forma essencial de democratização do Estado e da sociedade. A autonomia das mulheres - econômica, social, cultural e pessoal - é abordada como um dos pilares do novo ciclo de desenvolvimento sustentável e da garantia dos direitos das mulheres. A eliminação de todas as formas de discriminação, legais ou outras, passa pela garantia de seu desenvolvimento em todas as áreas, nomeadamente nos planos político, civil, econômico, social e cultural, de modo a assegura-lhes o exercício dos direitos humanos e das liberdades fundamentais.

Palavras-chave: Igualdade de gênero. Políticas para as mulheres. Direitos das mulheres. Direitos humanos.

\section{INTRODUÇÃO}

Este artigo busca refletir sobre a igualdade de direitos e dignidade humana inerente a mulheres e homens no contexto das Políticas Públicas para as Mulheres.

${ }^{1}$ Licenciada em Letras Português-Inglês pela Pontifícia Universidade Católica do Paraná - PUC/PR, Mestre em Teologia pela Pontifícia Universidade Católica do Paraná- PUC/PR. E-mail: angela.natel@fidelis.edu.br 
Neste prisma, o principal argumento aqui desenvolvido será a conquista das mulheres brasileiras, nas últimas décadas, na superação das desigualdades sociais e na ampliação dos direitos da mulher. As desigualdades e o problema da violência de gênero, que resultam de um processo de reprodução cultural, têm merecido grande atenção por parte dos movimentos feministas e das Conferências Mundiais sobre as Mulheres, tais como: O Programa de Ação da Conferência Internacional sobre População e Desenvolvimento (Cairo, 1994); a Conferência da Criança (1990); do Meio Ambiente (Rio, 1992); a Conferência Mundial de Direitos Humanos (Viena, 1993); o Plano de Ação da Conferência Mundial de População e Desenvolvimento (Cairo, 1994); a Cúpula para o Desenvolvimento Social (Copenhague, 1995), a IV Conferência Mundial sobre a Mulher (Pequim, 1995); a Cúpula do Milênio (2000); a Sessão Especial da Assembleia Geral sobre HIV (2001) e a Conferência contra o Racismo, a Discriminação Racial, que resultaram numa agenda cumulativa de recomendações de políticas públicas nas áreas de direitos humanos e políticas sociais e ambientais.

A criação de organismos voltados exclusivamente para as políticas para as mulheres e para a defesa dos direitos humanos da mulher é uma recomendação da IV Conferência Mundial, a Conferência de Beijing, realizada em 15 de setembro de 1995, na cidade de Beijing (Pequim) capital da China, em que foram tomadas decisões mais ousadas e concretas no que diz respeito à promoção da situação da mulher (ONU, 1995). Apesar de o status das mulheres ter avançado em alguns aspectos importantes nas últimas décadas, este progresso tem sido heterogêneo, desigualdades entre homens e mulheres têm persistido e sérios obstáculos também, com consequências prejudiciais para o bem-estar de todos os povos.

Na América Latina as políticas de gênero vêm se consolidando amplamente e operam como políticas transversais, que são articuladas por diferentes setores do governo, no intuito de reduzir às desigualdades na estrutura social e no combate contra as discriminações das mulheres. No Brasil, as ações dos movimentos feministas foram decisivas também para articular junto ao Estado políticas de redução das desigualdades entre homens e mulheres, de inclusão social, de empoderamento e de promoção da cidadania.

\section{AS POLÍTICAS DE GÊNERO E A TRANSVERSALIDADE DA CATEGORIA DE GÊNERO}

As políticas de gênero, além de operarem no plano econômico e político, visam atingir a própria dinâmica cultural, no sentido de contribuir para a construção de novas configurações culturais sobre os papéis sexuais. É importante salientar que essas políticas são iniciativas que 
emergem dentro de um contexto cultural global. De maneira específica, no Brasil, as políticas de gênero se traduziram em mudanças na legislação, uma produção crescente de estudos sobre a incidência desse fenômeno, a criação de delegacias especializadas e de serviço de atendimento às vítimas e a adoção de políticas públicas especializadas para combater o problema da violência. Essas mudanças têm seu fundamento na Constituição Federal de 1988, que, segundo Draibe (1989), representou um avanço significativo no que diz respeito ao modelo de proteção social brasileiro. A Constituição consagrou novos direitos sociais e princípios de organização da política social, permitindo alterar alguns pilares básicos do Estado de bem-estar social, ou seja, projetou um deslocamento do modelo meritocrático-particularista na direção do institucionalredistributivo, como modelo de proteção social de caráter mais universalista e igualitário. $\mathrm{O}$ fato da Constituição Federal ter inserido a dignidade humana logo no seu art. $1^{\circ}$, ao tratar dos fundamentos do Estado brasileiro, bem como os preâmbulos dos principais tratados internacionais de proteção da pessoa humana fazerem referência à dignidade do ser humano, são exemplos da relevância na proteção dos direitos e garantias individuais, além de conceder supremacia ao regime democrático. Com o intuito de salvaguardar todos estes direitos, erigiu a dignidade da pessoa humana como valor fundamental, como atributo e não como concessão por parte do Estado.

As inovações trazidas pela Constituição de 1988 ampliaram o acesso e a extensão dos direitos sociais, implementaram políticas públicas focalizadas no sistema de proteção social, tidas como importantes no processo de redução da pobreza e da desigualdade social. Surgem nesse contexto propostas de ações afirmativas direcionadas para minorias étnicas e para as mulheres, com caráter compensatório, cuja orientação visa corrigir desigualdades socioculturais e garantir os direitos dessas novas demandas. Entre estas, encontramos também as políticas de cotas para as mulheres, nas candidaturas políticas e as cotas para negros e indígenas, nas universidades e no serviço público federal.

No desenvolvimento de políticas para as mulheres, o movimento feminista brasileiro pode contar com os esforços da Secretaria de Políticas das Mulheres da Presidência da República (SPM/PR) criada em $1^{\circ}$ de janeiro de 2003, que atua não apenas na formulação, coordenação e articulação de políticas pela redução da desigualdade dos gêneros, mas também para ajudar no desenvolvimento econômico, social e humano, também objetivos fundamentais e requisitos essenciais para o desenvolvimento sustentável.

Nesse contexto é importante salientar que o direito fundamental à igualdade entre homens e mulheres pressupõe, inicialmente, que a dignidade da pessoa humana pertence tanto 
ao gênero masculino, como ao gênero feminino. Assim, “[...] todos os seres humanos, apesar das inúmeras diferenças biológicas e culturais que os distinguem entre si, merecem igual respeito, como únicos entes no mundo capazes de amar, descobrir a verdade e criar a beleza" (COMPARATO, 2003, p. 1). Scott define igualdade afirmando que "não é a ausência ou eliminação da diferença, mas sim, o reconhecimento da diferença e a decisão de ignorá-la ou de levá-la em consideração" (1999, p. 15). Cabe ressaltar que a noção de dignidade da pessoa humana envolve uma gama de considerações filosófica, cultural, política e histórica. O que se busca aqui é unir, na medida do possível, as formulações das políticas públicas na luta pelos direitos humanos para as mulheres.

\section{IGUALDADE DE GÊNERO E DE EMPODERAMENTO DAS MULHERES}

Revendo e analisando, comparativamente, momentos e percursos da história das mulheres, apercebemo-nos não obstante, empenhos e perspectivas de promoção e de valorização da mulher, biografias inconformadas com sua condição individual e coletiva. No Brasil, os estudos que tratam das relações de gênero acompanham os diferentes momentos dos movimentos sociais feministas. A partir da década de setenta a emergência destes movimentos sociais consolidam novas forças políticas. Movimentos sociais anticoloniais, étnicos, raciais, de homossexuais, ecológicos e de mulheres, para citar os mais expressivos, despontam e modificam lugares e mentalidades.

Um dos fatos mais emblemáticos foi a criação, em 1975 (Ano Internacional da Mulher), do Movimento Feminino pela Anistia. No mesmo ano a ONU, com apoio da Associação Brasileira de Imprensa (ABI), realiza uma semana de debates sobre a condição feminina. Ainda nos anos 70 é aprovada a lei do divórcio, uma antiga reivindicação do movimento. Mulheres da periferia, através das comunidades de Base da Igreja Católica, reivindicam ao Estado o atendimento das necessidades básicas como creches, melhores salários, reclamam do custo de vida e unem-se contra a pobreza. A reivindicação das creches era apontada como um dos principais problemas, pois as mulheres precisavam trabalhar fora para manter a família (TELES, 1993). Sem dúvida, estas reivindicações propiciaram não só mudanças de mentalidades como também mudanças no espaço urbano. No final da década de setenta as pesquisas voltam-se para as relações de produção. Mulher e trabalho, no espaço urbano ou rural, marcam os estudos de gênero, com destaque para os trabalhos das sociólogas Heleieth Saffioti (1978/ 1979/ 1981) e Eva Altermann Blay (1978). Nesse período, algumas mulheres militavam clandestinamente em grupos de esquerda contra a ditadura, propiciando, segundo Soares (1994), a emergência do feminismo dentro dos partidos de esquerda. Mas são as mulheres dos bairros populares que aparecem no espaço público construindo uma 
“dinâmica política própria” (SOARES,1994, p.16) e transformando o seu espaço cotidiano. Para Soares (1994, p.13) o "movimento de mulheres nos anos setenta trouxe uma nova versão da mulher brasileira, que vai às ruas em defesa de seus direitos e necessidades e que realiza enormes manifestações de denúncia de suas desigualdades".

Nos anos 80, as feministas embarcam na luta contra a violência às mulheres e pelo princípio de que os gêneros são diferentes, mas não desiguais. Em 1985 é criado o Conselho Nacional dos Direitos da Mulher (CNDM), subordinado ao Ministério da Justiça, com objetivo de eliminar a discriminação e aumentar a participação feminina nas atividades políticas, econômicas e culturais. O CNDM foi absorvido pela Secretaria de Estado dos Direitos da Mulher, criada em 2002 e ainda ligada à Pasta da Justiça. No ano 2003, a secretaria passa a ser vinculada à Presidência da República, com status ministerial, rebatizada de Secretaria de Políticas para as Mulheres.

Sem dúvida, no Brasil há uma trajetória significativa no planejamento que definiu o desenho das políticas de gênero nos últimos anos, envolve esferas do governo e a participação da sociedade civil nos diferentes níveis municipal, estadual e nacional. Nesse processo, destacam-se principalmente, a partir de 2004, as Conferências Nacionais de Políticas Públicas para as mulheres, que coordenadas pela Secretaria Especial de Políticas para as Mulheres e do Conselho Nacional dos Direitos da Mulher visam combater as discriminações e de promover a igualdade de gênero. A I Conferência de 2004 se constituiu um marco na afirmação dos direitos das mulheres e do início de um compromisso por parte do poder público com a construção da igualdade de gênero e a igualdade racial cujo compromisso dependia da elaboração de uma política de gênero com contribuições claras e bem definidas nas três esferas do Governo. Em ocasião da realização da I Conferência as plenárias municipais e estaduais enviaram quase quatro mil propostas indicativas de programas, cujas ações e projetos foram condensados pela conferência nos seguintes eixos temáticos:

1. Enfrentamento da Pobreza: geração de renda, trabalho, acesso ao crédito e a terra.

2. Superação da violência contra as mulheres - prevenção, assistência e enfrentamento.

3. Promoção do bem-estar e qualidade de vida para as mulheres: saúde, moradia, infraestrutura, equipamentos sociais e recursos naturais.

4. Efetivação dos direitos humanos das mulheres: saúde, moradia, infraestrutura, equipamentos sociais e recursos naturais.

5. Desenvolvimento de políticas de educação, cultura, comunicação e produção do conhecimento para igualdade (BRASIL, 2004, p. 6).

As diretrizes resultantes dessa I Conferência orientaram a elaboração do Plano Nacional de Políticas para as Mulheres (PNPM), focado para a ampliação do direito das mulheres e a 
construção da igualdade de gênero. Dessa forma, o Plano Nacional de Políticas para as Mulheres (PNPM) é tecido a partir das diretrizes definidas na I conferência Nacional de Políticas para as Mulheres (CNPM) realizada em julho de 2004, que representou um importante "marco na afirmação dos direitos da mulher e mobilizou, por todo Brasil, cerca de 120 mil mulheres que participaram, diretamente dos debates e apresentaram as propostas para a elaboração do I Plano Nacional de Políticas para as Mulheres" (BRASIL, 2005, p. 6).

Assim, o reconhecimento das mulheres como sujeitos de direitos e como sujeito político é parte das propostas para as políticas de gênero que visam promover maior acesso e participação das mulheres nos espaços de poder, como uma forma essencial de democratização do Estado e da sociedade. As ações do Plano remetem a uma ação política articulada com os diferentes setores do governo. O I Plano Nacional de Políticas para as Mulheres (I PNPM), (BRASIL, 2004) e o II PNPM (2004-2005) são exemplos contundentes da transversalidade de gênero nas políticas públicas, pois a partir deles desencadearam um conjunto de ações integradas entre os diversos ministérios, empresas públicas, governos estaduais e prefeituras, além da sociedade civil, que visam à melhoria da qualidade de vida das mulheres brasileiras (BRASIL, 2008).

O Compromisso com a promoção da "autonomia das mulheres" foi reafirmado na $3^{\mathrm{a}}$ Conferência Nacional de Políticas para as Mulheres, realizada em Brasília em 2011, quando o Estado brasileiro promoveu a "autonomia e igualdade das mulheres". Participaram cerca de 2.125 (duas mil, cento e vinte cinco) delegadas de municípios e estados, representando e defendendo propostas, indignações e reflexões políticas de mulheres e movimentos sociais de todo o país. A Conferência representou um momento importante para a consolidação e continuidade das lutas das mulheres por "um Brasil onde as desigualdades sejam superadas, e as diversidades, respeitadas e valorizadas" (BRASIL, 2013, p. 6).

O tema da igualdade de gênero e empoderamento das mulheres foi abordado também na Conferência das Nações Unidas sobre Desenvolvimento Sustentável, Rio +20. Um compromisso de gerações, realizada no Rio de Janeiro, 20 a 22 de Junho de 2012. A Conferência enfatiza o papel vital que as mulheres têm no desenvolvimento sustentável, garantindo sua participação plena e efetiva nas políticas, programas e tomadas de decisão em todos os níveis envolvendo o desenvolvimento sustentável. Lê-se no número 236 dos anais da conferência:

\footnotetext{
Reafirmamos o papel vital das mulheres e recordamos que elas devem participar, de forma plena e igual, na tomada de decisões em todas as áreas do desenvolvimento sustentável. Estamos dispostos a acelerar a implementação dos nossos respectivos compromissos a esse respeito, anunciados na Convenção sobre a Eliminação de Todas as Formas de Discriminação contra as Mulheres (CEDAW), bem como na Agenda 21, na Declaração da Plataforma de Ação de Pequim, e na Declaração do Milênio (ONU, 2012, n. 236, p. 47).
} 
Reforça-se, dessa forma, na Rio +20, a autonomia das mulheres - econômica, social, cultural e pessoal - como um dos pilares do novo ciclo de desenvolvimento e da garantia dos direitos das mulheres. A igualdade de gênero, considerada como equivalência social entre os vários gêneros, acelera o crescimento, reduz a pobreza, melhora as relações de poder e favorece o respeito pelos direitos fundamentais assegurados pela Constituição.

Assim, a equidade de gênero possibilita às mulheres a igualdade perante a lei, ou seja, a exclusão de toda discriminação arbitrária, tanto da parte do legislador, ao elaborar as normas, quanto da parte do juiz, na aplicação das normas aos casos concretos; Igualdade de direito, significando que as mulheres podem desfrutar igualitariamente, por parte de todos os cidadãos, dos direitos fundamentais assegurados pela Constituição; Igualdade de fato, referindo-se à igualdade na realidade; igualdade de oportunidades que supõem situar todos os membros de uma sociedade nas mesmas condições de partida, dando-lhes a mesma possibilidades para participar nos diversos âmbitos da sociedade; Igualdade de trato que consiste em tratar todos os indivíduos da mesma maneira, independentemente de sexo, raça, idade, religião, etc. e, por fim, igualdade de resultados em que todas as pessoas devem ter acesso ao mesmo ponto de chegada em cada uma das áreas nas quais se inserem e obter os mesmo benefícios das ações implementadas.

\section{DIREITO DAS MULHERES E SEUS RECONHECIMENTOS COMO DIREITOS HUMANOS}

Assinalamos nos parágrafos anteriores a importância da democracia para implantação de políticas públicas para as mulheres e a parceria histórica do Brasil com a ONU MULHERES para o fortalecimento de políticas de enfrentamento da violência contra as mulheres, contra a discriminação e o preconceito relacionados à raça, à etnia e à orientação sexual. A inclusão da noção de gênero e de igualdade entre mulheres e homens nas conferências internacionais e nacionais contribuiu para assegurar a implementação dos direitos humanos das mulheres e meninas como parte inalienável, integral e indivisível de todos os direitos humanos e liberdades fundamentais. Com a IV Conferência Mundial Sobre a Mulher, Pequim, 1995, o conceito de gênero passa de uma análise da situação da mulher baseada no aspecto biológico para uma compreensão das relações entre mulheres como produto de padrões determinados social e culturalmente, e, portanto, passíveis de modificação.

Sem dúvida, os fatores que têm introduzido essas transformações de longo curso são múltiplos e complexos. Os estudos sobre a mulher, sua participação na sociedade, organização familiar, movimentos sociais, política e trabalho adquiriram notoriedade no final da década de 80 
e início dos anos 90.

No âmbito de várias correntes de interpretações, procurou-se recuperar a atuação das mulheres no processo histórico como sujeitos ativos, fazendo emergir o enfoque cultural e destacando o social como historicamente construído em que as experiências sociais femininas e masculinas diferenciadas emergem numa condição própria em sociedades específicas. Nesse sentido, é importante observar as diferenças sexuais enquanto construções culturais, linguísticas e históricas, que incluem relações de poder não localizadas exclusivamente num ponto fixo - o masculino -, mas presente na trama histórica. Hoje, as trajetórias das mulheres são muito similares a dos homens. As mulheres estão nos espaços públicos do mundo do trabalho e da política, compartilham com os homens, embora nem sempre na mesma proporção, os espaços privados e as responsabilidades da reprodução social.

A ascensão das mulheres a cargos de representação política, a crescente presença em postos de decisão, se constitui um espaço adequado para o desenvolvimento de políticas transversais e uma força catalizadora para um consenso na comunidade internacional e nacional acerca da importância da inclusão das mulheres nas diversas áreas e para o desenvolvimento sustentável dos países. "Não haverá sustentabilidade, não haverá paz e não haverá futuro possível sem que as mulheres sejam definitivamente consideradas e incluídas em todos os processos, em todas as áreas e em todos os níveis”, afirmava Michelle Bachelet, secretária Geral Adjunta da ONU e Diretora Executiva da ONU Mulheres - Entidade das Nações Unidas para o Empoderamento das Mulheres para que os temas das mulheres sejam uma prioridade, no discurso Oficial de abertura da $3^{\text {a }}$ Conferência Nacional de Políticas para as Mulheres, realizada em Brasília de 12 a 15 de dezembro de 2011 (BRASIL, 2013, p. 14). Assim, a $3^{\text {a }}$ Conferência Nacional debruça-se no debate sobre a construção da autonomia econômica e social das mulheres, fundamental para alcançar a igualdade, ou seja, a equidade entre os gêneros.

É somente às portas do século XXI, que as defensoras dos direitos das mulheres conseguiram uma vitória significativa em insistir que seus direitos são direitos humanos e de que seu exercício é assegurado pelo sistema internacional de proteção. O Plano Estratégico para a Igualdade de Gênero e Empoderamento das Mulheres na CPLP², previsto na Resolução de Lisboa (4 de maio de 2010), estabelece linhas guias para a transversalidade das políticas de igualdade e equidade de gênero (BRASIL, 2010). A eliminação de todas as formas de discriminação, legais ou não, contra as mulheres passa pela garantia de seu desenvolvimento em todas as áreas, nomeadamente no plano político, civil, econômico, social e cultural, de modo a assegura-lhes o exercício dos direitos humanos e das liberdades fundamentais. Todos os direitos humanos são 
interdependentes, indivisíveis e universais. O reconhecimento dos direitos humanos das mulheres por parte da comunidade internacional significou tanto um começo como a culminação de um processo. Essa conquista representou em nível internacional e local o reforço de políticas voltadas para o fomento da educação e da capacitação das mulheres, e também pelo reconhecimento do trabalho das mulheres nos setores formal e informal da economia. Ao mesmo tempo, reforçou a necessidade de realização de campanhas conjuntas para o combate das formas específicas de discriminação de que as mulheres são vítimas, em particular sobre violência de gênero, nomeadamente violência doméstica, tráfico de seres humanos e preservativos femininos. Reforçase,ainda, a necessidade de se estabelecer uma agenda de Igualdade e Equidade de gênero no domínio da saúde, para o exercício pleno, por mulheres e homens, dos direitos humanos ao longo do ciclo de vida, em particular dos seus direitos sexuais e reprodutivos. Essas estratégias são também direcionadas para a redução das vulnerabilidades das mulheres, mulheres jovens e adolescentes ao HIV/Aids e a feminização da pandemia através da construção do seu empoderamento e da promoção do papel ativo das mulheres na prevenção, negociação e resolução dos conflitos nas operações de paz, na ajuda humanitária e nos processos de reconstrução das sociedades após os conflitos; na eliminação da violência de gênero, destacando a violência sexual, física e psicológica contra as mulheres.

\section{CONCLUSÃO}

Não obstante estas medidas, as mulheres ainda carecem de serem consideradas como atores e sujeitos dos direitos humanos plenamente reconhecidos e aplicados. A partir daí é possível um trabalho educativo mais consciente dentro dos aspectos de diversidade e inclusão. A incorporação da perspectiva de gênero nos direitos humanos requer uma nova concepção de dignidade humana. O valor da pessoa, enquanto conquista histórico-axiológica, encontra sua expressão jurídica nos direitos fundamentais do homem. A dignidade é atributo intrínseco da essência da pessoa humana, único ser que compreende um valor interno, superior a qualquer preço, que não admite substituição equivalente. A dignidade da pessoa humana não é uma criação constitucional, pois é um conceito a priori, um dado preexistente a toda experiência especulativa, tal como a própria pessoa humana. Segundo Bobbio, a Declaração Universal dos Direitos do Homem (1948), "contém em germe" a síntese de um movimento dialético, que começa pela universalidade abstrata dos direitos naturais, transfigura-se na particularidade concreta dos direitos positivos e termina na universalidade, não mais abstrata, mas também concreta, dos direitos positivos universais (BOBBIO, 1992). A

\footnotetext{
${ }^{2}$ A CPLP (Comunidade dos Países de Língua Portuguesa) constitui uma comunidade de países soberanos que livremente escolheram construir uma identidade comum. A CPLP é um espaço político, cultural e econômico geograficamente descontinuado cuja base assenta numa história comum, no respeito pelos direitos humanos, na defesa do estado de direito e da democracia, assim como na persecução de um desenvolvimento sustentável e socialmente justo. (Os países que compõe a CPLP são: Angola, Cabo Verde, Guiné-Bissau, Moçambique, Portugal, São Tomé e Príncipe e Timor-Leste.
} 
dignidade da pessoa humana e o exercício da cidadania são considerados princípios fundamentais da Carta Magna Brasileira de 1988. É por isso que se faz imprescindível uma política inclusiva no âmbito educacional, e que tanto homens quanto mulheres, sejam tratados com dignidade e valor intrínsecos.

\section{REFERÊNCIAS}

ASCEnSÃO, J. O. A Dignidade da Pessoa e o Fundamento dos Direitos Humanos.

Disponível em: http://www2.dbd.puc- rio.br/pergamum/tesesabertas/0613190_08_cap_02.pdf. Acesso em: 20.04.2019

BLAY, Eva. Trabalho Domesticado. São Paulo: Ed. Ática,1978.

BOBBIO, Norberto. A Era dos Direitos. Rio de Janeiro: Campus, 1992.

BRASIL. PRESIDÊNCIA DA REPÚBLICA. SECRETARIA DE POLÍTICAS PARA AS MULHERES. Plano Estratégico. Igualdade de Gênero e empoderamento das mulheres. CPLP. Disponível em: "http://www.spm.gov.br/Articulacao/articulacao-internacional/cplp/plano-estrategicoversao-final-cplp.pdf.\%20Acesso\%20em\%2020.03.2013". 20.03.2019

BRASIL. PRESIDÊNCIA DA REPÚBLICA. CONFERÊNCIA NACIONAL DE POLÍTICAS PARA AS MULHERES (3, 2011: Brasília-DF). Anais da $3^{\text {a }}$ Conferência Nacional de Políticas para as Mulheres: autonomia e igualdade para as mulheres. Brasília: Secretaria Nacional de Políticas para as Mulheres, 2013. 130 p. Disponível em: http://www.unwomen.org/2011/12/discurso-de-la-directora-ejecutiva-de-onu-mujeres-en-la-3 ${ }^{\mathrm{a}}$ conferencianacional- de-politicas-para-las-mujeres. Acesso em: 20.04.2019

BRASIL. PRESIDÊNCIA DA REPÚBLICA. BRASÍLIA: SECRETARIA ESPECIAL DE POLÍTICAS PARA AS MULHERES. Plano Nacional de Políticas para as Mulheres. Brasília, 2005, p. $6 . \quad$ Disponível http://bvsms.saude.gov.br/bvs/publicacoes/pnpm compacta.pdf. Acesso em 20.11.2019.

BRASIL. Presidência da República. Brasília. Secretaria Especial de Políticas para as Mulheres. Plano Nacional de Políticas para as Mulheres. 2004. Disponível em: http://bvsms.saude.gov.br/bvs/publicacoes/PNPM.pdf. Acesso em 20.01.2019

BRASIL. Presidência da República. Secretaria Especial de Políticas para as Mulheres. II Plano Nacional de Políticas para as Mulheres. Brasília: Secretaria Especial de Políticas para as Mulheres, 2008, p. 19. Disponível em: http://bvsms.saude.gov.br/bvs/publicacoes/II_PNPM.pdf. Acesso em: 20.01.2019.

COMPARATO, F. K. A afirmação histórica dos direitos humanos. São Paulo: Saraiva, 2004

DRAIBE, S. As políticas sociais brasileiras: diagnósticos e perspectivas. In: Políticas sociais e organização do trabalho. Brasília: IPEA-IPLAN, 1989, p. 1-63.

SCOTT, J, W. O enigma da igualdade. In: Estudos Feministas. Universidade Federal de Santa Catarina. Centro de Filosofia e Ciências Humanas, Centro de Comunicação e Expressão. v.7, n.12, (1999). Florianópolis: UFSC, 1999. 
SOARES, V. Movimento Feminista. Paradigmas e Desafios. Revista de Estudos Feministas. Rio de Janeiro: CIEC/ECO/UFRJ, N Especial, 2 Sem. 1994.

TELES, M. A. Breve História do Feminismo no Brasil. São Paulo: Brasiliense, 1993.

SAFFIOTI, H. Emprego Doméstico e Capitalismo. Petrópolis/Rio de Janeiro:Vozes,1978.

SAFFIOTI, H. A Mulher na Sociedade de Classes: mito e realidade. $2^{\mathrm{a}}$ ed. Petrópolis/Rio de Janeiro: Vozes,

SAFFIOTI, H. Do artesanal ao industrial: a exploração da mulher - um estudo das operárias têxteis de confecções no Brasil e Estados Unidos. São Paulo: Hucitec, 1981.

ONU. Conferência das Nações Unidas sobre Desenvolvimento Sustentável. Rio

+20 . Declaração final da Conferência das Nações Unidas sobre desenvolvimento sustentável (RIO + 20). O futuro que queremos. Rio de Janeiro, Brasil, 20 a 22 de junho de 2012, n. 236, p. 47. Disponível em: https://www.utl.pt/admin/docs/4808 O-Futuro-que-queremos1.pdf. Acesso em: 04.04.2019).

ONU. Declaração e Plataforma de Ação da IV Conferência Mundial Sobre a Mulher. Pequim, 1995, p. 152. Disponível em: http://www.spm.gov.br/Articulacao/articulacaointernacional/relatorio-pequim.pdf. Acesso em:

"http://www.spm.gov.br/Articulacao/articulacao-internacional/relatoriopequim.pdf.\%20Acesso\%20em\%2002.10.2012" 02.10.2018.

VATICANO II. Constituição dogmática Lumen Gentium sobre a Igreja. In: Vaticano II. Mensagens, discursos e documentos. 2. Ed. São Paulo: Paulinas, 2007. 